\title{
Higher Education, de-centred subjectivities and the emergence of a pedagogical self among Black and Muslim students
}

Pete Harris, Chris Haywood and Mairtin Mac an Ghaill

\begin{abstract}
This article explores late modern Black and Muslim young men's and women's experiences of higher education. Carrying out qualitative research with 14 male and female young people, these students claimed that their Youth and Community Work course at their university made available an alternative representational space, enabling them to develop a major transformation of their sense of identity and self. In deploying the term pedagogical self, we are attempting to capture their naming pedagogy as central, in their terms, to the 'reinvention of their selves'. We conclude by suggesting that our research participants' narratives are located within an exploration of late modern identity and the self in higher education. In turn, this enables us to reflect on a generational shift in meanings around racialization and difference in thinking about the future of higher education in Britain
\end{abstract}

Key words

Pedagogy, self, generation, higher education, racialization

\section{Introduction}

James:

I'm glad I've come on this course and I really want to finish with a high grade and just prove to myself that I could and be a bit of a role model to people around me that will see me graduate and see the possibilities for themselves and hopefully to show other people it's possible, symbolic capital. Have my little picture on the wall of me graduating, my certificate. I guess it's going to help me grow in my practice, the kind of support I can offer to young people as well.

Hameeda: Looking back, I feel for us on our course we've made something of ourselves....something important. I never liked school, it was bad but I always knew I liked learning. And here it all came together, all the discussions, all the arguments 
and everything. For the first time in our lives, we believed in ourselves and each other and it's great... It's like we came into uni and now we're going out a completely different person. And we can pass this on in our professional practice.

Currently, for black and Muslim young men and women, much political, media and academic commentary serves to re-inscribe them as a major social problem for the state. This representation builds on the histories of British higher education that are littered with discarded images of diasporian groups, marked by homogenisation, dysfunction, failure, lack of voice, marginality and invisibility (Bird, et al, 1992). In an earlier period, questions about 'anti-racist' practice across educational sectors in response to pervasive racial discrimination revolved around collective mobilisation against institutional racism (Law 1996). More recently, structured inequality has been reframed as individual failure as the neoliberal discourses of individual responsibility and choice drive de-racialised subjects in the cultivation of knowledge and skills deemed to be in global market demand (Haywood and Mac an Ghaill 2013). This is occurring within the context of a performative-based higher education system, at a time of the emergence of an assertive English nationalism involving a forging of a renewed British identity and a European-wide political questioning about stateled multiculturalism and a shift to securitisation (Miah 2015).

This paper seeks to build on previous work on black and Muslim student experience in higher education (Bagguley and Hussain 2014; Burke et al, 2012). Critically engaging with dominant representations of minority ethnic failure as individual choice, we draw upon a qualitative analysis of student narratives to explore a changing cultural condition that is inhabited by a younger generation of British born, working class, black and Muslim students (of Pakistani and Bangladeshi heritage). Against a pessimistic trend in the literature 
concerning a lack of promotion of ethnic/racial equality, the students in this study, as illustrated above by James and Hameeda, claimed that their Youth and Community Work course at a post 1992 University in the Midlands made available an alternative representational space, enabling them to develop a major transformation of their sense of identity and self. Much writing in the literature addressing questions of late modern identity and the self in education operates within an identity politics framework and our research participants generally shared this perspective (Mirza 2015). However, in deploying the term pedagogical self, we are attempting to capture their naming pedagogy as central, in their terms, to the 'reinvention of their selves'. The students referred to a range of themes that might be identified as constituting the pedagogical self that included: the central role of the lecturers; dialogical encounters with peers and inter-subjective recognition of the self in the 'other'; earlier educational experiences and a new (academic) literacy to name past and current experiences.

The paper begins with a discussion of our methodological approach, followed by a section on the literature and current empirical studies we drew upon exploring late modern identity and the self in higher education, as a context for setting out our research participants' narratives. This enables us in a final section to address reflections on a generational shift in meanings around racialization in thinking about the future of higher education in Britain.

\section{Making methodological sense: Young men and women's narratives}

The Youth and Community Work course is grounded in a mix of theoretical discourses, most notably Paulo Freire's (1972) notion of 'dialogical' education. The aims of the course are to: equip students with the knowledge, understanding and skills required to achieve professional status in Youth and Community Work and to be a reflective practitioner; ensure that students are able to base their professional practice on a systematic understanding of the key aspects 
of youth and community work, and be able to apply this in different contexts; promote the development of key transferable skills necessary for employment including: the exercise of initiative and personal responsibility, decision-making in complex and unpredictable contexts, the ability to work as a member of a team and autonomously, and the learning ability needed to undertake appropriate further training; ensure a supportive learning environment which develops students' confidence and intellectual curiosity; and to enable students to adjust to the demands of learning at HE level and function in a modern professional environment including acquiring information and digital literacy. Operating as an applied, vocational course, students also learn experientially in the field often in local communities affected by poverty and social exclusion. Acting as gatekeepers to a 'profession', Youth and Community Work courses traditionally embrace a 'community of practice' model (Lave and Wenger 1991), where students learn experientially in the field under practice supervisors, who enable students to make links between practice and theory.

For this small-scale research project, we carried out unstructured interviews with eight black (five female and three male) students and six Muslim (two female and four male) students. The interviews lasted between 60 and 90 minutes and the students chose the location where they felt most comfortable to be interviewed within the institution. Throughout our conversations with the students, questions of contested understandings, interpretations and meanings were central, operating within specific higher education institutional power/knowledge configurations. It is important to note that diasporian social groups are highly diverse and as a qualitative and explorative study, the article does not seek inductive validity by suggesting that the participants represent the experiences of the broader diasporian groups of the general population. Instead, as Crouch and McKenzie $(2006,493)$ argue:

Rather than being systematically selected instances of specific categories of attitudes and responses, here respondents embody and represent meaningful 
experience-structure links. Put differently, our respondents are "cases", or instances of states, rather than (just) individuals who are bearers of certain designated properties (or "variables").

The exploration of the students' meaningful experiences was a key objective of the research design. The interviews were supplemented by a range of other research strategies that included observations and informal conversations, informed by our wider critical ethnography on the impact of globally-inflected change upon the local formation of diasporic younger generation's subjectivity and identity (Mac an Ghaill and Haywood 2014; Appadurai 1991). The data was subject to thematic analysis (Braun and Clarke, 2006) that enabled us to explore '...the underlying ideas, constructions, and discourses that shape or inform the semantic content of the data' (Ussher et al, 2013, 3). The subsequent analysis was taken back to the students themselves not simply as a form of 'face validity' but also as a way of exploring the practical and political implications of the findings. All interviews throughout the study were anonymized and the research participants were given pseudonyms.

\section{Higher education, identity formation and the production of a pedagogical self}

Bernstein's (2000) socio-cultural theory of education enables us to make a fundamental critique of neoliberal discourses of British teaching and learning, with its emphasis on an overly individualised entrepreneurial self. More specifically, the key concept of pedagogy opens up a broader understanding of teaching. Bernstein's work has had a major influence on critical educationalists over the last few decades. This is most recently illustrated in Burke et al's (2012) text in which they suggest: 'We understand pedagogies as lived, relational and embodied practices in higher education. Although hegemonic discourses at play in education policy construct largely instrumentalized notions of teaching and learning, the dynamics, relations and experiences of teaching and learning are intimately tied to the re/production of 
particular identity formations and ways of being a university student and teacher' (9). Bernstein's work enables us to begin to formulate a concept of the 'pedagogical self' with its suggested shift from teaching as a simple practice of transmission of knowledge from teacher to student to pedagogy as a dynamic multi-dimensional practice of critical engagement with and among peers and lecturers, that resonates with our students' current institutional experience.

At a time of the demise of structuralist theories, Bourdieu (1997) continues to be analytically central to understanding the (class) reproduction of education. More particularly, he is one of the major influences on 'capital' being used as an analytical framework in explaining the relationship between (in)equality, social mobility and higher education among minority ethnic groups. Within a British context, Modood (2012) has established his own analytical approach, in which social capital and ethnic capital have been key features, in exploring South Asian/Muslim experiences of higher education. Modood's work, alongside a range of other recent researchers, including Basit (2013) and Crozier and Davies (2006) carrying out studies on educational, social and ethnic forms of capital have made a major contribution in challenging earlier pathologised representations, especially of young British Muslim/South Asian women. However, in relation to the young men and women with whom we were working, these theories tended to underplay generationally-specific understandings of subjectivity, identity formation and the self, in other words processes of subjectification (Davies 2006).

It is important to explore the generational specificity and how the pedagogical-self interplays with young people's subjectivities. Bagguley and Hussain (2014) in critiquing social capital theory, claim that the concept reflexivity provides such a generationally-specific 
understanding of young people's experiences of higher education at a time of rapid shifting change with reference to equality, social mobility and differential subjective reflexivity. Drawing upon Archer $(2007,4)$, they write:

She suggests that reflexivity is characteristic of all individuals who hold internal dialogues mediating between their social circumstances and their actions. This explains how structural constraints and enablements operate through human agency. People's course of actions are products of their reflexive deliberations and their subjectively determined personal projects in relation to the social and cultural circumstances objectively confronting them. Some of these objective circumstances will be known, but others will be unacknowledged conditions of action. It is enough to know that the unacknowledged conditions are there, but not the details of their operation, nor do they have to be 'internalised'.

Much of the theoretical legacy of social capital theory continues to appear to be derivative of a first generation migrant experience. For Bagguley and Hussain, Archer's work provides a more productive framework than social capital theory in explaining 'changes in educational outcomes' within communities (3). They are particularly interested in South Asian women's subjectivity, agency, and social mobility, referring to them as reflexive commentators, whose social practices have much in common with the students in our study.

For our students in their discussion of academic representations of higher education, the ongoing narrative (and research) of the post-war immigration of South Asian/Muslim and black communities is still being told in an older generationally specific language of race and empire that is not able to grasp the specificities of a younger emerging inter-ethnic and inter- 
religious social relationships and their engagement with a different de-centred racial semantics, as Chhaya illustrates here.

Chhaya: You look at unis and they're full of black and Asian people, especially young Muslim women, like lots of other young women, they've changed what unis look like. They don't want to keep hearing about failure. We need to think about how to build on this success to break the glass ceiling at work. These young women, this younger generation, have a different way of looking at things, different experiences, different meanings, and I think they will do it.

Post-colonial writers have made an important theoretical contribution in providing new frameworks that address the issues raised by the students. These writers enable us to move beyond the reductive black/white colonial paradigm, to make sense of new ethnicities, decentred subjectivities and syncretic cultures around the politics of race and nation (Hall 1992; Brah, et al, 1999). Within the context of higher education, a main claim of this work on racial difference is that we cannot simply read off social relations from fixed oppositional categories of blacks and whites, marked by ethnic boundedness, fixity and social separation, in making sense of students' pedagogical experience. We suggest that an empirically based critical analysis located within higher education, enables us to conceptualize a response to emerging identifications and de-centred subjectivities among students by viewing them as a set of narratives of 'self-production' that are dispersed through a multiplicity of power relations that are actively secured. As Kevin illustrates below, the students suggested this as constituting a generational difference with their parents' experience (see McLean 2011).

Kevin: I think that most theories about black people going onto to university, it's about our parents' generation, about people not born in Britain. It's all that deficit ideas about 
us, about oppression, a 1970s model....but now we need to look at how we are successful, how people are getting through.

The students are not simply talking about increasing numbers of black and Muslim/South Asian students now in higher education but significantly are making reference to their own educational biographies. As we suggested in the introduction, much writing in the literature addressing questions of late modern identity and the self in education speaks of multiple identities and selves in terms of subjects inhabiting the major social categories of gender, sexuality, ethnicity or class, and most recently religion (Mirza 2015). The students inhabited educational trajectories that were embedded in late modern understandings of cultural difference at individual and collective levels. However, in deploying the term pedagogical self, we are attempting to capture the students naming pedagogy as central to the 'reinvention of their selves' and accompanying de-centred subjectivities, contributing to their selfrecognition of their 'becoming someone'. Foucault's (1978) earlier work on the production of identity formation and selfhood has been influential in critical educational research, although at times it tended to emphasise the regulation and disciplining of the subject. In his later work, Foucault has suggested exploring identity as a technology of the self, where subjectivity is a socio-historical formation of dispersed institutional arenas of power (Foucault 1988). This work develops the notion of agency, enabling us to explore more sensitively the specific historical dynamics of the production of complex and diverse racialized/ethnic subjectivities (Bagguley and Hussain 2014). One of the main concepts adopted by recent theorists is the notion of the techniques of the self, that is modern forms of managing/producing the self. Foucault speaks of four types of techniques 'that he says agents practise on themselves to make themselves into the persons they want to be' (Martin et al, 1988,18). They are: technologies of production, which permit us to produce, transform or manipulate things; technologies of power, which determine the conduct of individuals; 
technologies of sign systems, which permit us to use symbols of signification; 'technologies of the self, which permit individuals to effect by their own means a number of operations on their own bodies and souls, thoughts, conduct, and way of being so as to transform themselves in order to attain a certain state of happiness, purity, wisdom, perfection or immortality' (Martin et al 1988,18). As Nixon (1997, 323) maintains, of particular significance here is that: 'Foucault's comments on 'practices of the self' open up the possibility of conceptualising the articulation of concrete individuals to particular representations as performance based upon the citing and reiteration of discursive norms; a performance in which the formal positions of subjectivity are inhabited through specific practices or techniques'.

We now move to use the above theoretical insights in analysing our research participants' narratives about their recent experiences of higher education. As we indicated in the introduction, reading through their narratives a range of inter-connecting themes can be identified with reference to the constitution of the pedagogical self, that included: the central role of the lecturers; dialogical encounters with peers and inter-subjective recognition of the self in the 'other'; earlier educational experiences and a new (academic) literacy to name past and current experiences.

\section{Central Role of Lecturers}

A major theme that the students returned to throughout the fieldwork was the critical importance of the lecturers on the youth and community course in the co-production of a pedagogical self (Bhopal and Danaher 2013).

Leonie: How did it all start? The biggest thing was the lecturers believing in us. Yes, even when there were lots of tensions and angers and confusion and silences in the discussions, they stuck with us and believed in us. Then, we began to believe in 
ourselves. It was like when we came into the lecture room a light went on and we became new people.

Smita: It seemed like the first time we could really discuss important things. At the time, it seemed it was all about learning new theories and new ways of thinking and arguing. A big thing was listening to people and their ideas that you did not agree with.... But the biggest thing we were learning was about ourselves. It's strange, we've all trained as youth and community workers and we're in situations at work where we never stop discussing things. So, what was so different about this place with these people and these lecturers? Because this was a teaching, a learning place.

Sukhdip: It seemed like the lecturers were transforming us at the start, by the end of the first year, you could see, we were changing ourselves in important ways. It was like being in a play, sometimes the lecturers were the directors, sometimes we were directing ourselves. I think even the lecturers were learning things from us.... Imagine going back to school and telling the teachers what happening to their little pupils that they wrote off all those years ago.

Of central significance for the students on the course was that they were encouraged to think critically at a time when they were intrinsically motivated to do so; with each other, and with lecturers. This was achieved by bringing theory into the visceral, embodied experience of lectures and small tutor groups and by working to bring tacit, unconscious processes into a learnable, theoretical framework. In this sense, the process of self-development became part of the pedagogical purpose of the course. The use of "generative themes" (Freire 1972) that emerged from the students' own reality and were raised by them were considered central to this process. The students were highly motivated to examine how they were positioned within their social world, when engaged in an educative process that began with themes drawn from 
their immediate, concrete reality. This allowed for both seemingly trivial and significant aspects of their own lives to be first discovered, named, and then imbued with meaning. In turn this enabled them to act more autonomously and in ways that precipitated their personal development and change within their changing social reality.

\section{Dialogical Encounters with Peers and Inter-subjective Recognition of the 'Other'}

Much of the earlier work both in anti-racist theory and social capital theory with reference to Black and South Asian/Muslim students' educational experiences have under-played their complex identifications, affiliations, investments and positionings. More specifically, within the location of higher education, we know little about the complex processes of subjectivity and accompanying processes of subjectification, inter-subjectivities and social biographies, complex investments/affiliations and the occupying of multiple and diverse identifications (Benjamin 1998). For our students, equally of critical significance as their lecturers in the development of the pedagogical self, was their interaction with their peers. They claimed that the university was an institutional space that provided them for the first time in their lives with an opportunity to meet a wide range of people with different life experiences with whom to engage in critical dialogue.

Joanne: I feel there is definitely an ethos of, like...equality, and anything, any kind of oppression is challenged....there is a space for dialogue... so even if people do have views that I wouldn't like or question, I have to force myself to listen acceptingly and people are allowed to say whether it's right or wrong. We can air these topics and it feels like it's important, these aren't just side issues.

The students were on the Youth and Community Work course during a specific period that included the increasing visibility of the 'Muslim question' and the re-racialisation of Muslims 
within Britain and across Europe (Mac an Ghaill and Haywood 2014; Miah 2015). The critical dialogue among peers and between peers and lecturers covered a wide range of educational, political, biographical and ethical issues, including providing a unique institutional 'safe space' to discuss faith and identity. Significantly, discussions that began in lecture rooms were continued among small groups of students in various leisure spaces across the university. One of the most visible friendships to develop, in which the inter-subjective recognition of the self in the other was to the fore, was between a Muslim student and a white student, who was a former soldier .

Iftikhar: If we talk about Dave over a period of time, with his background, with my views, I feel I can have that conversation with him because I'm assured that actually he understands better than most others where I am coming from, than anybody else....me and Dave are starting to get a better understanding of each other.... Listening to Dave, talking to him, actually seeing his physical expressions when he is talking about that stuff gives a better understanding, you know, that he's actually been through a lot. : ...not crossed it, but we are on that bridge, understanding each other and I wouldn't have wanted to have left here... and not been on that bridge of conversation with Dave, and we're here now and hopefully within the next semester, we can get somewhere with that and that for me would be a huge step because I'm actually starting to understand the other side.

Some of the students were especially keen to uncover the inter-subjective, dialogical processes at work within pedagogical interactions In line with other analyses of student experience (Lucey, Melody and Walkerdine 2006) we see merit in making use of the work of Jessica Benjamin who is concerned with how parties within a relationship make known their 
own subjectivity and learn to perceive and appreciate that of the 'other'- a process she calls recognition. Judith Butler defines recognition as,

A process that is engaged when subject and other understand themselves to be reflected in one another, but where this reflection does not result in a collapse of the one into the other (Butler 2004, 311-12).

We utilised this concept in relation to the narratives we gathered from students as we sought to understand their engagement in a kind of semiotics of self, through which they came to personify a set of values informed by the critical pedagogy which they were collectively creating in their undergraduate course. We incorporated a notion of reciprocity to capture the simultaneous, two-way, processes whereby students 'co-produced' with each other and tutors a sense of a new self - which we refer to as the 'pedagogical self'.

Earlier Educational Experiences and A New (Academic) literacy to Name Past and Current Experiences

One of the most visible elements for the students, in the development of the pedagogical self, was the acquisition of a new 'academic' literacy. This manifested itself in several ways, including being able to name past and current experiences and imbue them with meanings and reflexively to articulate self-representations to themselves and others. A major institutional sign of their success was that these students, who entered university with low academic qualifications completed the course with top grades, including several of them gaining first class degrees.

Kevin: Coming to Uni I've learnt about different theories, I guess, like, things that I felt.... frustrated with....you know, anxious about in my life. I always 
knew they were there, because I felt them, but couldn't really describe them. But coming here I've learnt about things that I can give a label to.

Iftikhar: You know, I think I'm working at a different..... how can I put it? This way... my reflection, the way I live now is at a different algorhythm, if I can put it that way, compared to before I came and my own understanding of myself.

Earlier in the paper, we spoke of the pedagogical self as dynamic and creative. One of the most impressive examples of this throughout the students' narratives was their reflecting on their own early educational experiences and how their new self was transforming their personal, domestic and professional lives (Mirza 2015). This is a long way from the imagined autonomous 'entrepreneurial self' that is prescribed by neoliberal educational policy with reference to social mobility and widening participation.

Khalid: In Asian families there is a big pressure for children to look after their parents when they get older..... For me, I went out to get a job early to support my family.... What's different now is that I'm bringing home cultural capital rather than money. What I've got from this course affects the whole family, including my brothers and nieces..... Everyone is very proud and of course they've all supported me over the years, so really, it's their success as well.

Khalid's comments are interesting from several perspectives. First, as suggested above, the use of 'generative themes' (Freire 1972) that emerged from the students' own reality and were raised by them were of central significance to the constitution of the pedagogical self. The students were constantly questioning how they were positioned within their social world, when engaged in an educative process that began with themes drawn from their immediate, 
concrete reality. Such engagement resonates with Freire's notion of a 'generative theme', which he suggests is a cultural or political topic of great concern or importance to people from which discussion can be generated. These generative themes can be represented in the form of 'codifications' (words, short phrases or visual representations), which people can then step back from and decode or explore critically by regarding them objectively rather than simply experiencing them. For the students, this was a central aspect of their learning, enabling them to intervene and initiate change in society, particularly with reference to the oppressive conditions experienced by their families and communities.

Second, Khalid's comments are also interesting within the context of the recent shift in policy discourse from a focus on multiculturalism to surveillance and securitisation (Miah 2015). Such recent government discursive shifts, including the suggestion that a younger generation of Muslims need to adopt British values sees a return to an assimilationist model that was put in place for a first generation of post-war migrants. Such a model, based on a false dichotomy between (religious) tradition and (secular) modernity assumes that the latter must be embraced by young Muslims by displacing and distancing themselves from the former. As Khalid finely illustrates the students were in the process of developing late modern reflective biographies by drawing upon family collective resources and accompanying values. This more nuanced understanding of racialization, racial positioning and subjectivity was reflected on throughout the research period and is explored in the next section with reference to generational shifts of meaning (Crozier and Davies 2006).

\section{Making sense of generational shifting meanings of racialization: from colonial-based race to post-colonial ethnicity}


When we first read the students' narratives, we had a sense of a generational shift from a colonial-based understanding of racial inequality marked by structural discrimination and collective mobilisation against institutional racism to the politics of identity formation, marked by ethnic /religious subjects, individual consciousness and multi-culture (Hall 1992). As we re-read these narratives and in discussion with team members of the Youth and Community Work course, we began to see a more complex picture of different students combining diverse emphases on the structural and identity making aspects of Muslim and Black experiences of higher education (Mac an Ghaill 1999). However, most of the students appeared to position themselves within what might be called a late modernity sensibility, highlighting a sense of reflexivity, fragmentation, ambivalence, individuality and multiple/shifting identities. Their thinking might be captured by Bauman's (2001) notion of Liquid Modernity. Thus, within the context of their course, students were developing subjectivities that were marked by 'their fragmentariness and discontinuity, narrowness of focus and purpose, shallowness of contact' (Bauman 1996, 34). In other words, their sense of identity appeared to be no longer premised on fixed identity categories enabling a multitude of discourses of religion, 'race'/ethnicity and class to temporarily cohere. Furthermore, it could be argued that their narratives suggest a space that might exist outside neoliberal discourses of individualism, choice and entrepreneurialism. The pedagogical self could be understood as an active reflexive project, where as Fadeeva and Mochizuki $(2010,250)$ point out: '... the transition from "solid" to "liquid" modernity has challenged individuals to find alternative ways to organise their lives, for social forms no longer have enough time to solidify and cannot serve as frames of reference for human actions'. The liquid nature of their narratives is discussed further below. 
Within the context of exploring the research literature on British higher education and antiracism, among our participants, we found a range of complex, nuanced and differentiated student narratives with reference to global, national and local histories. A sense of liquidity can be found in the generationally specific individual and collective negotiation with and resistance to multiple forms of racism and faith hate, resonant of a wider politics of culture involving overlapping territories and intertwined histories (Said 1993). For example, within the interviews some students appeared to operate with what might be referred to as a certain cultural amnesia about structuralist-based 'old racial times'. When we discussed the idea of the anti-racist university, they displayed a primary interest in interpersonal social relations, that is, interactions between staff and students and among students themselves, as primarily indicative of the presence or absence of racism.

Lisa: We have a lot of experience of racism as youth workers and this place is definitely not racist. Just look at how people get on together.... I'd say there's a lot of respect for each other for everyone of different communities.

Farzana: This is definitely a safe space for Muslim students.... Islamophobia is everywhere in this country at a really high level.... but not, definitely not here.

There was a general reluctance to locate racism within the structure of the institution, or more specifically, the geographical and social space in which they were now located, preferring to see it more as a function of the point or place in which they found themselves in what they referred to as 'their own biographical journey'. 
Sukhdip: I don't think it has anything to do with the institution, for me anyway, it was about the students and myself in regards to, you know, how we engage with people, everybody engages with people in different ways.

Other students incorporated earlier versions of anti-racism that informed their own generationally-reflexive scripts that were spoken within more individual identity-based inflected accounts of social and cultural exclusions, with a strong sense of the interconnection of multiple categories of exclusion and the emergence of the racialization of a wide range of social groups, including recent East European migrants and refugees and asylum seekers (Mirza 2015).

Leonard: Over the years I've shifted from just thinking of a black perspective and all the systemic racism on blacks to thinking about others who have a lot of prejudice and stereotyping. Like the recent migrants and refugees I work with. These discussions would have been very different 20 years ago, now there is more emphasis on how racism affects individuals and all the talk we had on the course of the different identities, like a lot and big arguments about working class identities and where poor white kids fit on the map of oppressions.

There was also a smaller group who articulated an explicit commitment to an anti-racist or anti-Islamophobic politics, around a race/ colour consciousness or religious adherence.

Farzana: On the course we discussed the deep structures of racism. It often came up. Maybe a lot of people, maybe most don't seem to be interested in that anymore. But for me, yes, it's still the same, maybe some things have improved in some ways. But mainly on the surface. What's really changed is that white people cannot say the racist stuff openly and they feel offended by this, because for them they are just speaking 
what they really feel. The exception is that you can say openly what you feel about Muslims. There is so much Islamophobia now.

Michael: It's like the term racism isn't really understood anymore. Of course black and Asian people still end up at the bottom on schools, jobs, bad housing, extreme poverty, etc., etc. It's not an individual prejudice, it's systemic across society...And, then a celebrity calls a black person coloured and the person is labelled racist. It's mad. We're all celebrating diversity, when the country has never been so racially divided.

Students maintained that they were re-negotiating these understandings throughout the course. Their narratives suggested that pedagogical practices addressing contemporary racial inequality are mediated through a wide range of generationally-specific meanings among black and Muslim students that have continuities and discontinuities with an earlier generation of new social movement theories of (higher) educational oppression, racial inequality and cultural/religious difference. Furthermore, in trying to make sense of their meanings, it should be noted that we know little about the specificity of the cultural resources that they can call upon as individual subjects, who have vast professional expertise as youth and community workers. It is against this background, that they, as university students, narrate their shifting and diverse meanings of (ethnic/religious) identity formation and racialization within late modern conditions of socio-economic austerity. We attempted to make sense of our research participants' narratives by framing them in terms of their working through a tension between a (colonial based) materialist understanding of race and raced subjects and that of a post-colonial ethnicity and accompanying de-centred subjectivities that included an awareness of social majorities as ethnic/religious subjects 
Materialist explanations of racism have been a central aspect of the education/training of youth and community workers over the last few decades (Sallah and Howson 2007). Materialist refers to social movements that perceive the organisation of ethnic and racialized identities as deriving from fixed bases of social power. Such bases of social power are seen to work logically and predictably, often being illustrated through an individual's occupation of fixed hierarchical positions, such as dominant/empowered (white people) and subordinate/oppressed (black people). (Mac an Ghaill 1999). This materialist position was historically important in shifting the focus of analysis away from the assumption of ethnicity acting as a barrier to black and South Asian working class students accessing higher education to an emphasis on the commonalities of the social and cultural reproduction of racism experienced by South Asian and black students operating across institutional life.

The materialist explanation of racism continued to have resonance for the students in this study, whose experience of postcolonial Britain involves socio-economic austerity, increasing inequalities, regional socio-economic disparities and the success of UKIP in local and European elections providing evidence of an emerging new nationalism and an accompanying re-racialisation of diasporian social groups, which has become highly explicit in the period after the Brexit vote for Britain to leave Europe (Versi 2016). The students as youth and community workers have experienced this assertive English nationalism After Empire (Gilroy 2004), within the context of different communities being impelled to live with different racialised realities in an increasingly socio-economically and spatially divided society. This re-racialisation is most immediately experienced in their daily lives, as a result of the intense surveillance that differentially impacts on diasporian groups and their location, spatially, socio-economically, generationally and subjectively. At a time when commentators 
speak of a post-racial politics, the students' caseloads in the recent past indicate the historical continuity of racially inflected class based structural constraints on black and Muslim communities. The latter's collective profile includes the highest levels of unemployment and over-representation in low skilled employment, over-representation in prisons, overrepresentation in poor housing, high levels of poor health and lowest levels of social mobility (Garner and Bhattacharyya 2011; Equality and Human Rights Commission 2016).

Minakshi: Austerity has massively increased divisions in this city....poor people, white people as well minority communities have been hit the hardest.

Marcella: For minorities in Britain, my mother says life has got better because there's not the overt racism of the 70s. But if you look at racism working through poverty and extreme hostility from people in power it's really gone backward. Perhaps, it's also more complex now because, white poor people are also really despised.

As suggested above, a majority of the students tended not to refer to a materialist understanding of racism when discussing their current experience of university life. Rather, in their social biographies, it was invoked in remembering experiences that were marked by various forms of symbolic violence, social exclusion, misrecognition as well as gender specific forms of racialisation in their earlier schooling. The interviewees' narratives were particularly of interest as they had experience of a wide range of educational institutions: primary school; comprehensive and grammar secondary schools; further education; a Russell Group university; and, a children's home. Most of the students' narratives illustrated the pervasiveness of racial exclusion that helped shape their childhood and young adult lives across educational sites. Hence, there is no simple shift from colonial-based understandings of raced subjects and racism to late modern ethnicity within post-colonial conditions. 
However, the latter might be interpreted as forming a primary focus of many of their narratives about their current pedagogical experience.

Joanne: Well the teaching here reflects that we're born here, doesn't it? It would be different if it were our parents' generation. Lots of things have changed and got more complex. Like all the talk about identity, our generation, we've grown up with identity politics.

Iftikhar: And then the crisis about British identity. It's very important especially for young people, young white people I work with. They're looking for an identity too, maybe the most, and they've got all the issues, like unemployment, homelessness, a lot of things against them....with no-one listening to them, except the far right.

\section{Conclusion}

We began this research with a focus on exploring current experiences of the anti-racist university. Against the pessimistic trend in the literature concerning the promotion of racial equality and engendering institutional change in H.E. in the post Race Relations (Amendment) Act (2000) period, the students in this qualitative study spoke of their university experience as the place where an emerging pedagogical self was imagined and lived out as part of a wider process, where subjectivities, identifications and identities became reconfigured. The students tended to work with decentred notions of race, ethnicity and racism. As late modern subjects, they spoke of the pedagogical opportunities offered by the youth and community course to reflect on multiple identities and subjectivities that enabled them to re-read their earlier educational biographies - reflecting on the interconnections between their past, present and future. The wide range of theories of racisms and ethnicities to which they were introduced, together with their own cultural capital that the former enabled them to recognise, has helped them to produce sophisticated, nuanced narratives 
about contemporary racialisation, grounded in their professional biographies as youth and community workers. Most significantly, they are writing their own narratives about their futures.

\section{References}

Alvesson, Mats and Kay Skoldberg. 2000. Reflexive Methodology: New Vistas for Qualitative Research. London: Sage.

Appadurai, Arjun. 1991. Global Ethnoscapes: Notes and Queries for a Transnational anthropology. In Recapturing Anthropology: Working in the Present, edited by Richard G. Fox, 191-210. Santa Fe, CA: School of American Research.

Archer Margaret, S. 2007. Making Our Way through the World: Human Reflexivity and Social Mobility. Cambridge: Cambridge University Press.

Bagguley, Paul and Yasmin Hussain. 2014. Negotiating mobility: South Asian Women and Higher Education. Sociology, IFirst: 1-17.

Basit, Tehmina, N. 2013. Educational capital as a catalyst for upward social mobility amongst British Asians: a tree-generational analysis. British Educational Research Journal 39(4): 714-32.

Bauman, Zygmunt1996. From pilgrim to tourist or a short history of identity. In Questions of Cultural Identity, edited by Stuart Hall and Paul du Gay, 18-36. London: Sage.

Bauman , Zygmunt 2001. Liquid Modernity. Cambridge: Polity Press.

Bernstein, Basil. 2000. Pedagogy, Symbolic Control and Identity: Theory, Research, Critique. (Second edition) Lanham: Rowman and Littlefield Publications. 
Benjamin, Jessica.1998. Shadow of the Other: Intersubjectivity and Gender in Psychoanalysis. Routledge: New York

Bhopal, Kalwant and Patrick Danaher. 2013. Identity and Pedagogy in Higher Education. London: Bloomsbury.

Bird, J. John, Azar Sheibani, A. and Diane Francombe, D. 1992. Ethnic Monitoring and Admissions to Higher Education. Employment Department/Bristol Polytechnic.

Bourdieu, Pierre 1997. The forms of capital. In Education, Culture, Economy, Society, edited by A. H. Halsey, Hugh Lauder, Phillip Brown and Amy Stuart Wells, 46-58. Oxford: Oxford University Press.

Brah, Avtar, Mary, J. Hickman. and Mairtin Mac an Ghaill. eds. 1999. Thinking Identities: Ethnicity, Racism and Culture. Basingstoke: Macmillan Press.

Braun, Virginia and Victoria Clarke. 2006. Using thematic analysis in psychology. Qualitative Research in Psychology 3(2): 77-101.

Burke, Penny Jane, Gill Crozier, Barbara read, Julia Hall, Jo Peat and Becky Francis. 2012. Formations of Gender and Higher Education Pedagogies. Gap, Final Report, the Higher Education Academy, National Fellowship Scheme, London: University of Roehampton.

Butler, Judith 2004. Undoing Gender. London: Routledge.

Crouch, Mira and Heather McKenzie. 2006. The logic of small samples in interview-based qualitative research. Social Science Information 45(4): 483-499.

Crozier, Gill and Jane Davies. 2006. Family matters: A discussion of the Bangladeshi and Pakistani extended family and community in supporting the children's education. The Sociological Review 54(4): 678-95. 
Davies Bronwyn. 2006. Subjectification: the relevance of Butler's analysis for education, British Journal of Sociology of Education 27(4): 425-38.

Equality and Human Rights Commission 2016 Healing a Divided Community: The Need for a Comprehensive Race Equality Strategy. Equality and Human Rights Commission, https://www.equalityhumanrights.com/sites/default/files/healing_a_divided_britain_the_need_for_a_comprehensive_race_equality_strategy.pdf. (accessed on 18th August 2016).

Fadeeva, Zinaida and Yoko Mochizuki. 2010. Higher Education for Today and Tomorrow: University Appraisal for Diversity, Innovation and Change towards Sustainable Development. Sustainability Science 5: 249-256.

Foucault, Michel. 1978. An Introduction. Volume 1 of The History of Sexuality. New York: Random House.

Foucault, Michel. 1988. Technologies of the self. In Technologies of the Self: A Seminar with Michel Foucault edited by Luther H. Martin, Huck Gutman and Patrick H. Hutton. 16-50. London: Tavistock.

Freire, Paulo 1992. Pedagogy of the Oppressed. Harmondsworth: Penguin.

Garner, Steve and Gargi Bhattacharyya. 2011. Poverty, Ethnicity and Place. York: Joseph Rowntree Foundation.

Gilroy, Paul 2004. After Empire: Melancholia or convivial culture. London: Routledge.

Hall, Stuart. 1992. The question of cultural identity. In Modernity and Its Futures, edited by Stuart Hall, David Held, and Tony McGrew. Cambridge: Polity. 
Haywood, Chris. and Mairtin Mac an Ghaill. 2013. Education and Masculinities: Social, Cultural and Global Transformations. London: Routledge.

Lave, Jean and Wenger, Etienne. 1991 Situated Learning: Legitimate Peripheral Participation. Cambridge: Cambridge University Press.

Law, Ian. 1996. Racism, Ethnicity and Social Policy. London: Prentice Hall.

Lucey, Helen, Jane Melody and Valerie Walkerdine. 2006. Uneasy hybrids:

psychosocial aspects of becoming educationally successful for working class young women. In The Routledge Falmer Reader in Gender and Education, edited by Madeleine Arnot, and Mairtin Mac an Ghaill, 238-251. London: Routledge.

Mac an Ghaill, Mairtin. 1999. Contemporary Racisms and Ethnicities: Social and Cultural Transformations. Buckingham: Open University Press.

Mac an Ghaill, Mairtin and Chris Haywood. 2014. British born Pakistani and Bangladeshi Young Men: exploring unstable concepts of Muslim, Islamophobia and racialization. Critical Sociology 41(1): 97-114.

Martin, Luther, H., Huck, Gutman, H., and Patrick, Hutton. eds. 1988. Technologies of the Self: A Seminar with Michel Foucault. London: Tavistock.

McLean, Monica 2006. Pedagogy and the University: Critical Theory and Practice. London: The Continuum International Publishing Group.

Miah, Shamim. 2015. Muslims, Schooling and the Question of Self-segregation. Basingstoke: Palgravemacmillan.

Mirza, Heidi, S. 2015. Decolonizing higher education: Black feminism and the intersectionality of race and gender. Journal of Feminist Scholarship, 7/8:1-12.

Modood, Tariq. 2012. Capitals, ethnicity and higher education. In Social Inclusion and Higher Education edited by Tehmina N. Basit and Sally Tomlinson Policy: Bristol. 
Nixon, Sean 1997. Exhibiting masculinity. In Representation: Cultural representations and signifying practices, edited by Stuart Hall London: Sage/The Open University Press. Race Relations (Amendment) Act 2000. London: UK Government.

Said, Edward (1993) Culture and Imperialism. London: Vintage.

Sallah, Momomdou and Howson, Carlton 2007. Working with black young people, Lyme Regis, Russell House.

Ussher, J. M, Sandoval, M, Perz, J, Wong, W. K. T., and Butow, P. 2013. The Gendered

Construction and Experience of Difficulties and Rewards in Cancer Care, Qualitative Health Research, http://qhr.sagepub.com/content/early/2013/04/03/1049732313484197

Versi, Miqdaad. 2016. Brexit has given voice to racism - and too many are complicit. The Guardian, 27 June 2016. 